Résumés des conférences et travaux

\title{
Philologie et historiographie du Caucase chrétien
}

Jean-Pierre Mahé

\section{OpenEdition \\ Journals}

Édition électronique

URL : https://journals.openedition.org/ashp/970

DOI : 10.4000/ashp.970

ISSN : $1969-6310$

Éditeur

Publications de l'École Pratique des Hautes Études

Édition imprimée

Date de publication : 2 février 2011

Pagination : 33-36

ISSN : 0766-0677

Référence électronique

Jean-Pierre Mahé, "Philologie et historiographie du Caucase chrétien », Annuaire de l'École pratique des hautes études (EPHE), Section des sciences historiques et philologiques [En ligne], 141 | 2011, mis en ligne le 23 février 2011, consulté le 06 juillet 2021. URL : http://journals.openedition.org/ashp/970 ; DOI https://doi.org/10.4000/ashp.970 


\title{
PHILOLOGIE ET HISTORIOGR APHIE DU CAUCASE CHRÉTIEN
}

\author{
Directeur d'études : M. Jean-Pierre MAHÉ, \\ membre de l'Institut
}

Programme de l'année 2008-2009 : I. L'Arménie et les Arabes (639-884). — II. La royauté bagratide (884-1055).

\section{L'Arménie et les Arabes (639-884)}

Du point de vue, nécessairement rétrospectif, de l'historien contemporain, la domination arabe en Arménie, du VII ${ }^{\mathrm{e}}$ au IX $X^{\mathrm{e}}$ siècle, est plus qu'un tournant décisif. C'est une véritable rupture. Rien ne sera plus après comme avant. Ne serait-ce qu'en raison de l'érosion territoriale et démographique. L'Aghdznik, au sud-ouest, ainsi que les provinces occidentales, de Satala à Palin et Arsamosate sont définitivement perdues. Ce qui reste de l'Arménie majeure est largement entamé par des foyers de colonisation musulmane : les émirats d'Avnik, de Mastaton, de Qalikala et de Salmast; les états kaysites autour de Manazkert, chaybanide près de Mayyafarkin, outhmanide à Berkri, et zouraride entre Bitlis et Arzan. De nombreux Arméniens ont émigré à l'ouest, dans les régions de Sébaste, Mélitène et Césarée de Cappadoce. À l'exception des Bagratouni, des Haïkides du Siounik et des Artsrouni du Vaspourakan, l'ancienne aristocratie a été presque entièrement éliminée. Changements irréversibles, qui laissent des plaies inguérissables.

Pourtant, au regard des contemporains, qui découvraient les événements au jour le jour, sans en pressentir le dénouement, les premières décennies de la période furent plutôt considérées comme une sorte de retour en arrière, de rétablissement des franchises perdues, indûment confisquées par l'étranger. Certes, les Arabes s'étaient tout d'abord imposés par la guerre et par la violence. Mais la « protection » qu'ils avaient accordée aux Arméniens au milieu du VII ${ }^{\mathrm{e}}$ siècle était beaucoup moins exigeante que la tutelle sassanide ou l'administration byzantine. Laissant toute liberté aux chrétiens, ils ne se mêlaient pas, contrairement aux Perses, de nommer le catholicos, et ils ne prétendaient pas, comme les Byzantins, imposer la foi chalcédonienne. L'administration califale ne contestait pas alors le pouvoir ancestral des dynastes, chacun dans sa principauté. Le peuple vivait selon sa coutume sur un territoire national totalement réunifié plus de deux siècles après le partage de 387 . C'est pourquoi la seconde moitié du VII ${ }^{\mathrm{e}}$ siècle fut, dans l'ensemble, une période heureuse, où l'âge d'or de l'architecture arménienne, amorcé à la fin du siècle précédent, atteignit son apogée et livra ses plus grands chefs d'œuvre.

Par contraste le VIII ${ }^{\mathrm{e}}$ siècle est une époque de révoltes, toujours suivies de sanglantes répressions. En passant du protectorat à l'administration directe, les Arabes contrariaient de front l'organisation coutumière dont ils avaient naguère favorisé la 
restauration. Ils tentèrent à plusieurs reprises de supprimer le pouvoir des dynastes et d'éradiquer les familles princières. Les franchises religieuses concédées au temps du catholicos Yovhannes Odznetsi furent remises en cause par les Abbassides. L'Église fut dépouillée du patrimoine qu'elle avait conservé depuis l'époque arsacide. Les congrégations monastiques furent bientôt dispersées et ne se reconstituèrent que dans les années 870.

À la même époque, la fiscalité devenue écrasante s'allégea considérablement. L'artisanat local et le commerce international retrouvèrent une indéniable prospérité. $\mathrm{Au}$ terme d'une longue et douloureuse recomposition de l'aristocratie arménienne, les Bagratouni, profitant du déclin de leurs concurrents et des tensions entre le califat et les émirs locaux, transformèrent la dispersion de leurs domaines, aux marges du pays, en une politique d'encerclement qui leur permit de conquérir progressivement tout le Nord et le Nord-Ouest.

Néanmoins, il serait aventureux de conclure, de cette tardive accalmie, que le califat ait apporté à l'Arménie le moindre bénéfice culturel. À «l'âge d'or » du VII siècle n'avaient succédé que des ruines. La science d'Anania Chirakatsi, vers 670, ne doit rien à la science arabe, qu'elle devance de plus d'un siècle et demi. C'est plutôt le califat qui s'est enrichi des cultures chrétiennes, arménienne et syriaque.

On comprend que les Arméniens se soient fait une idée de plus en plus sombre de l'islam et de son fondateur. Alors qu'au VII ${ }^{\mathrm{e}}$ siècle, le Pseudo-Sebeos voit en Mahomet un marchand fort versé dans « l'histoire mosaïque », qui ramène ses compatriotes à la connaissance du vrai Dieu, le catholicos Yovhannes, qui achève sa chronique en 924, estime que la religion du Prophète « était un athéisme qui ne trompait que les esprits des ignorants; sa croyance était une fausse doctrine; ses louanges, des infamies; sa foi, une détestable infidélité; ses sacrifices, des actions impures; ses actions généreuses, des atrocités ». Tovma Artsrouni achève de sataniser le personnage en imputant ce que le Prophète croit savoir de Jésus ou de l'Ancien Testament à des accointances hérétiques ou démoniaques. Selon lui, Mahomet parodie la vie du Sauveur : il ne fait retraite au désert que pour y entendre la voix du diable; au lieu de monter un âne, comme Jésus à Jérusalem, il chevauche un chameau; il remplace le baptême par des ablutions, et le paradis par la débauche; s'étant fait fort de ressusciter, il finit dévoré par des chiens.

La coexistence était-elle donc impossible entre la coutume arménienne et la civilisation islamique? Cristallisée au $\mathrm{x}^{\mathrm{e}}$ siècle, l'épopée orale des Trompe-la-mort $d u$ Sassoun laisse un moment supposer le contraire. Au sultan d'Égypte, qui se plaint de la révolte de Davit l'Arménien, sa mère Ismil Khatoun réplique : «Si tu avais fait ce que je t'ai dit, si tu lui avais rendu visite deux fois l'an, et si tu l'avais invité chez toi, il aurait été si heureux de penser : “j'ai un frère!" ». Le sultan objecte : "Comment serait-il mon frère, puisque je suis arabe et qu'il est arménien? » Sa mère insiste : « Ne le comprends-tu pas? Beaucoup d'Arabes et d'Arméniens sont frères et se rendent mutuellement service ». Mais pour Davit, c'est déjà trop tard. Les Arabes sont devenus des ennemis dont il faut triompher grâce à « la croix des batailles, au pain, au vin et au Seigneur vivant ». Le destin global de la lignée des héros épiques illustre par un apologue les dangers de la compromission avec les charmes vénéneux de l'islam. Alors que leur ancêtre Baghdasar, parti pour Bagdad avec son épouse, sera privé de 
descendance, son frère, Sanasar, qui demeure au Sassoun, engendre une race de preux. Par conséquent, dans la mentalité arménienne de l'époque, il n'est point de salut que de se replier dans les montagnes et de rompre avec les Arabes.

\section{La royauté bagratide (884-1055)}

Rien ne serait plus illusoire que de se figurer l'avènement d'Achot Bagratouni, proclamé roi le 26 août 884 , comme une sorte de restauration de l'antique monarchie arménienne des Artaxiades ou des Arsacides.

La cérémonie de couronnement présidée par le catholicos Georg (879-898) n'eut guère plus qu'une portée symbolique. La couronne remise à Achot, « avec des habits royaux, des présents, des marques d'honneur, des coursiers rapides comme l'air et harnachés avec armes et parures ", ne signifiait pas la reconnaissance d'un droit ancestral, mais une concession du calife. Au contraire des anciens rois d'Israël, dont les Bagratouni prétendaient descendre, le nouveau monarque ne reçut pas d'huile sainte. Comme l'onction était le privilège du catholicos, on se contenta, pour le roi, « de divines prières de bénédictions spirituelles ».

Par ce rite, Achot était investi d'une autorité royale sur « la maison de Torgom » et « la race d'Achkenaz ». Toutefois le statut international de l'Arménie et des autres États caucasiens n'en ressortait pas transformé : désormais le calife s'abstiendrait d'envoyer des gouverneurs en Armîniya, mais le pays continuerait d'être tributaire, comme par le passé ; il était donc devenu autonome, sans avoir recouvré sa pleine souveraineté. C'est pourquoi ni Achot ni ses successeurs ne se crurent autorisés à frapper des pièces de monnaie à leur nom ou à leur effigie. En fin de compte, la royauté bagratide ne reposait pas sur des bases juridiques ou institutionnelles, mais sur une conjoncture internationale favorable et sur l'habileté personnelle des monarques.

Toutefois l'équilibre des forces entre le Califat arabe décadent et l'Empire byzantin en cours de recomposition, qui avait permis, dans la seconde moitié du $\mathrm{IX}^{\mathrm{e}}$ siècle, l'émergence d'une nouvelle indépendance arménienne, prit fin vers le milieu $\mathrm{du} \mathrm{XI}^{\mathrm{e}}$ siècle, quand Basile II et ses successeurs achevèrent la reconquête de l'Anatolie et de la Syrie. Statu quo toléré par les grandes puissances, l'émancipation de l'Arménie ne fut jamais reconnue de plein droit. Byzance n'accepta jamais ni l'autocéphalie de l'Église arménienne, ni le statut royal des gouvernants arméniens. Les califes oscillèrent constamment entre le dialogue direct avec les monarques bagratides et leur subordination à l'émir d'Azerbaïdjan, successeur des gouverneurs de l'ancienne Armîniya.

Cette instabilité fut grandement favorisée par les divisions des Arméniens euxmêmes. Bien que les répressions arabes du VIII ${ }^{\mathrm{e}}$ siècle, décimant les familles princières, eussent ruiné les bases sociales du dynastisme préislamique, les Arméniens n'inventèrent pas de nouvelles formes de gouvernance. Les Bagratouni n'eurent ni le projet ni les moyens de créer un état centralisé. Confrontés aux divisions de leurs rivaux, Artsrouni et Siouni, ils les aggravèrent eux-mêmes en donnant des apanages à leurs cadets. Seul Gagik I ${ }^{\text {er }}$ réagit vigoureusement, mais il était déjà trop tard pour arrêter l'avancée byzantine. 
En supprimant l'indépendance arménienne, scrupuleusement respectée par les deux empereurs byzantins les plus glorieux, Constantin et Héraclius, Basile II ne renouait pas seulement avec l'autoritarisme funeste d'un Justinien. Il rompait avec un principe bien établi depuis le premier siècle de notre ère : la position intermédiaire de l'Arménie entre l'Empire et les puissances du Moyen-Orient. S'estimant assez forts pour lutter contre les États musulmans sans le concours actif des Arméniens et de leurs alliés géorgiens et abkhazes, Basile II et ses successeurs méconnurent gravement le rôle millénaire du Caucase, barrière de civilisation contre la barbarie des steppes.

L'efficacité de l'administration byzantine, organisant méthodiquement l'exil des princes et le départ des populations, rompit, plus radicalement que les violences califales, le lien des Arméniens avec le sol de leurs ancêtres. Elle entraîna un durable glissement démographique vers la Cappadoce et la Cilicie, où devaient se former des principautés arméniennes au lendemain de la bataille de Mantzikert (1071), qui livra l'Anatolie aux Seldjoukides.

Bien que Basile II eût totalement récupéré l'héritage de David le Curopalate, le royaume unifié de Géorgie, dont celui-ci avait favorisé la formation, fut épargné par l'annexion byzantine. C'est de là que devait venir la reconquête chrétienne de l'Est anatolien. 